\title{
A tribute to Donald W. Seldin
}

W April 25, 2018, academic medicine has lost one of the brightest stars in its galaxy. Seldin (Figure 1) was born in Brooklyn, New York, in 1920 and grew up there during the Great Depression. In 1940, he graduated from NYU, where he focused first on the humanities and, only in his senior year, went on to premedical science courses. During World War II, he attended Yale Medical School (New Haven, Connecticut, USA) and graduated in 1943 with the highest honors. Then, accelerated by the war, he served a medical residency at the Yale-New Haven Hospital.

Seldin was inducted into the Army and, at the age of 26, became chief of the medical service and head of the clinical laboratory of a large Army hospital in Munich (1). While there, he served as an expert witness at the military trial of a Nazi physician who had conducted human experiments leading to many fatal outcomes at the Dachau concentration camp. The physician was convicted and condemned to death, in part on Seldin's testimony. This experience had a profound effect on Seldin, leading him to refer to it in articles and speeches on morality and bioethics, and it influenced him decades later when he served as a key member of the National Commission for the Protection of Human Subjects of Biomedical and Behavioral Research.

After discharge from the Army, Seldin returned to Yale, where he served as an instructor and assistant professor of medicine from 1948-1950. He joined the Metabolism Section in the Department of Medicine, headed by John P. Peters. Peters was regarded as a great scholar of medicine and became a model to Seldin and many others. While intellectually stimulated and personally happy at Yale, Seldin found the section on metabolism to be crowded with excellent young faculty, and he questioned whether it offered him much of an academic future. He was offered a position as an associate professor at a small, relatively young school, the University of Texas Southwestern Medical School (UT South-

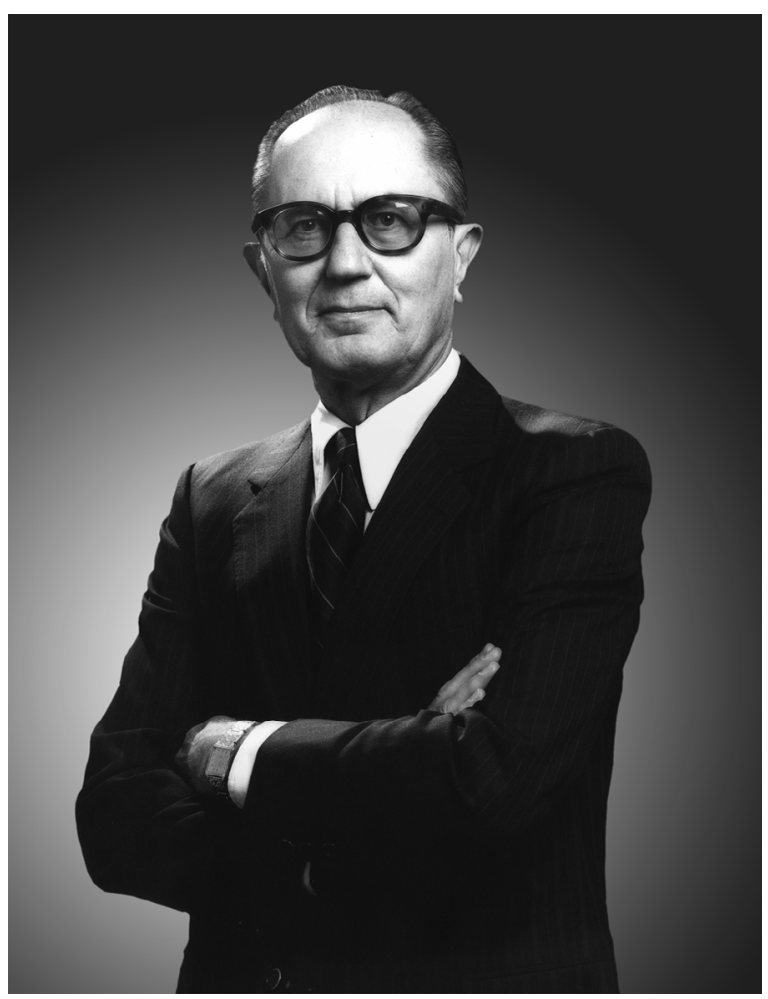

Figure 1. Donald W. Seldin. Image credit: David Gresham, UT Southwestern.

western) in Dallas, Texas. Seldin accepted the position, sight unseen, and drove to Dallas with his wife and daughter. He was shocked to find that the school was composed of only a very small number of fulltime faculty housed in a few run-down, abandoned Army barracks. The nearby Parkland Hospital, the school's teaching hospital, was also in very poor condition. Soon after his arrival, the chair of internal medicine who had recruited him departed. In 1952, at the age of 32, Seldin - the only remaining full-time member of the department - became chair by default. There was no organization of the curriculum or quality control of the teaching by volunteer private practitioners. The school was placed on probation by the national accrediting agency. Seldin wondered whether he had made a grave mistake in moving from Yale and explored the possibility of returning (2).

He decided, however, to accept the challenge of developing an academic department of medicine. Despite a severe shortage of funds, he moved rapidly to create rigorous, exciting teaching programs for students and house staff. He was an eloquent and charismatic teacher, with formidable creative energy and a strong commitment to excellence. Since he could not afford to hire postdoctoral fellows for his own research program, he enlisted the assistance of promising medical students. These included, among others, Floyd C. Rector Jr., Jean Wilson, Daniel W. Foster, Norman M. Kaplan, and Jere H. Mitchell - all of whom became distinguished physician-scientists and members of the American Society for Clinical Investigation (ASCI). Soon, a new dean - George N. Aagaard - was appointed, and with Seldin's help, he convinced the state to support building new facilities for the medical school and convinced the county to build a new Parkland Hospital. Things were beginning to look up!

Although resources for recruiting were still limited, Seldin managed to bring outstanding new faculty into the department, such as Leonard L. Madison and 
Roger Unger at the Dallas VA hospital, Marvin D. Sipirstein from the NIH, and Morris Ziff from NYU. However, he built his department largely by sending particularly promising former students and residents elsewhere for further training with the hope that they would return. Decades later, in his acceptance of the Kober Medal from the Association of American Physicians, Seldin spoke of his early years in Dallas, saying, "It was possible to work with students and house staff. Studentfellows soon became house officers and went away for postgraduate fellowship training. Many were touchingly loyal and returned to become faculty members and colleagues. In a real sense, whatever luster the department had was conferred upon it mainly by returning students, house officers, and fellows" (3).

Early in his chairmanship, Seldin became convinced that genetics was going to play a critical role in the future of medicine. Accordingly, he sent one of his most promising graduates, Joseph L. Goldstein, to the Massachusetts General Hospital for house staff training, to the NIH for laboratory training with the Nobel Prize-winning geneticist Marshall W. Nirenberg, and finally to the University of Washington for training in clinical genetics by Arno G. Motulsky. Michael S. Brown had been a coresident with Goldstein and, subsequently, also trained at the NIH. Goldstein and Seldin teamed up to recruit Brown to the UT Southwestern Department of Medicine. The Brown-Goldstein team characterized the low-density lipoprotein cholesterol receptor and described its function; they became the first of six Nobel Prize winners at UT Southwestern. Based on the enormous accomplishments of many of his former trainees, Seldin developed the reputation of being an outstanding judge of "academic horseflesh."

All faculty members in the department were expected to remain capable in general internal medicine, as well as in their subspecialty, and to be active teachers and researchers - the so-called triple threats. Seldin himself was their role model, as a world-class renal physiologist, a scintillating teacher, and a brilliant clinician committed to humane, rational clinical care. He practiced and taught "Precision Medicine" decades before these words entered the vocabulary. For years, he kept up with each medical subspecialty and read every paper written by members of his department. Seldin created a culture of excitement about biomedical science and its basis for clinical medicine. This excitement grew over the years and extended to the entire medical school.

Seldin's research focused on renal physiology and pathophysiology (4). He and his colleagues studied the renal production of ammonia, regulation of the osmolality of body fluids, and how these may be deranged by disease. His work in collaboration with Floyd C. Rector Jr. was particularly illuminating. They examined the renal reabsorption of bicarbonate, a key process in regulating acid-base balance. In whole-dog studies, they established that the administration of potassium markedly depressed the capacity of the kidney to reabsorb bicarbonate and that it can thereby be responsible for the development of metabolic acidosis. They inferred that the action of potassium may be mediated by a process in which intracellular alkalinization plays a significant role. They confirmed this inference with micropuncture studies on rat nephrons and described the complex interplay between extracellular fluid volume, its potassium concentration, and the action of adrenal steroids in the control of bicarbonate reabsorption, which may result in the generation of metabolic alkalosis by the kidney. They also showed that mineralocorticoids accelerate sodium absorption in the distal nephron (4). In 1965, Suki, Rector, and Seldin published a key paper on the mechanisms of a (then) new, especially powerful sulfonamide diuretic, furosemide, which has remained a cornerstone in diuretic therapy world-wide (5). They showed that furosemide enhances solute-free water clearance, exerting its profound effect on the ascending limb of the loop of Henle. In contrast, other (weaker) sulfonamide diuretics, such as chlorothiazide, inhibit water reabsorption in a cortical diluting segment. Beginning in 1985, Seldin coedited with Gerhard H. Giebisch five editions of a classic text entitled The Kidney: Physiology and Pathophysiology, which has become very important to renal physiologists and pathophysiologists (6).

In the 1960s, Seldin became concerned about increasing societal pressures on medical schools and feared that responses to these pressures could have a deleterious effect on academic medicine by reducing the time and energy of the faculty. In his Presidential Address to the ASCI in 1966, he stated, "We are now confronted from all quarters with the demand to undertake clinical service responsibilities far beyond what is required for academic purposes" (7). Although these views were controversial, they fell on fertile soil. While, in the past half century, academic medical centers have certainly expanded their efforts on behalf of societal health, perhaps because of Seldin's early warnings, most medical schools have developed departments or divisions such as family medicine and general internal medicine to help protect the school's more academic functions.

Seldin was a founder of the American Society of Nephrology and a major figure in identifying nephrology as a major subspecialty of internal medicine. He established one of the first divisions of nephrology in a department of medicine. More than 200 graduates of the Division of Nephrology at UT Southwestern became leaders in academic nephrology around the world. Kevin Longino, the head of the National Kidney Foundation, wrote the following in a history of the field: "Nephrology in the US is what it is today because one day, many years ago, Seldin decided to make it his major area of interest" (8).

Seldin served as president of seven scholarly organizations, including the ASCI, the Association of American Physicians, and both the American and International Societies of Nephrology. He was awarded six honorary doctorates, including one from Yale. His other honors included election to the National Academy of Medicine and the American Academy of Arts and Sciences. He has received numerous awards including the Kober Medal of the Association of American Physicians and the Distinguished Chairman of Medicine Award from the Association of Professors of Medicine, as well as key awards from the American, International, and German Societies of Nephrology and the National Kidney Foundation.

Seldin's personal qualities gained the deep loyalty of his trainees and faculty. With his enormous dedication to UT Southwestern, this loyalty to him was extended to the institution and greatly strengthened it. Seldin played a semi- 
nal role in transforming a small medical school into an enormous world-class medical center. No faculty member has had a greater impact on their school than Donald Seldin.

In his later years, Seldin was a towering figure, a true medical statesman. His wise counsel was widely sought, freely given, and deeply appreciated by many leaders of academic medicine and by universities and organizations from around the world. When these are added to the thousands of students, residents, fellows, and faculty at the UT Southwestern Medical Center whom Seldin inspired, it is clear that his influence on academic medicine for two-thirds of a century was broad, profound, and unique.

In addition to his intense commitment to medicine, Seldin maintained a lifelong passion for the arts, especially classical music, poetry, literature, and sculpture. He had three children and two grandchildren with his first wife, Muriel, who died in 1994. He is survived by his devoted wife, Dr. Ellen Taylor Seldin.

A simple statement by Michael S. Brown says it all: "Medicine has never seen and will never see his equal."

\section{Eugene Braunwald, M.D.}

Address correspondence to: Eugene Braunwald, Department of Medicine, Brigham and Women's Hospital, Harvard Medical School, 60 Fenwood Road, 7th fl, Boston, Massachusetts 02115, USA. Email: ebraunwald@partners.org.

\footnotetext{
1. Seldin D. A conversation with Donald Seldin. Interview by Ushma Neill. J Clin Invest.
}

2012;122(8):2707-2708.

2. Seldin DW. Donald Wayne Seldin, MD: a conversation with the editor. Interview by William Clifford Roberts. Proc (Bayl Univ Med Cent). 2003;16(2):193-220.

3. Seldin DW. Acceptance of the George M. Kober Medal for 1985. Trans Assoc Am Physicians. 1985;98:148-150.

4. Rector FC Jr. Presentation of the George M. Kober medal to Donald W. Seldin. Trans Assoc Am Physicians. 1985;98:132-147.

5. Suki W, Rector FC, Seldin DW. The site of action of furosemide and other sulfonamide diuretics in the dog. J Clin Invest. 1965;44:1458-1469.

6. Alpern R, Caplan M, Moe OW, eds. Seldin and Giebisch's The Kidney. 5th ed. Cambridge, Massachusetts, USA: Academic Press; 2012.

7. Seldin DW. Presidential Address: American Society for Clinical Investigation. Some reflections on the role of basic research and service in clinical departments. J Clin Invest. 1966;45(6):976-979.

8. Massry SG, ed. The National Kidney Foundation: The First 40 Years. Philadelphia, Pennsylvania, USA; Saunders: 1990. 